\title{
Medical care ideals among urban and rural residents in Thailand: a qualitative study
}

Tomoki Ikai ${ }^{* *}$, Saowalak Yamtree ${ }^{2}$, Takuji Takemoto ${ }^{3}$, Taro Tamura ${ }^{4}$, Hitomi Kanayama ${ }^{4}$, Kazuhiro Sato ${ }^{4}$, Yukinori Kusaka ${ }^{4}$, Hiroyuki Hayashi ${ }^{5}$ and Hidekazu Terasawa ${ }^{6}$

\begin{abstract}
Background: Health care is generally considered to be more highly valued in urban areas than in rural areas. However, studies have reported that there is no difference in the health care values of urban and rural areas in the Kingdom of Thailand, with some studies even indicating that these values are stronger in rural areas. We, therefore, conducted interviews and implemented a qualitative investigation and analysis aimed at elucidating ideals relating to the medical environment among the Kingdom's urban and rural citizens.
\end{abstract}

Methods: The study targeted Thai citizens residing in urban and rural areas. The city of Khon Kaen, located in Khon Kaen Province in northeastern Thailand, was selected as the urban area for the study. We selected Donyang village, located in the same province, as the rural study area. In July 2014, we conducted semi-structured group interviews, applying the Constructivist Grounded Theory (CGT) analytical approach.

Results: We interviewed ten people in Khon Kaen (the urban area) and seven people from Donyang village (the rural area). Five major and distinctive themes emerged from the interviews. These were: locally appropriate standards of medical care, support for local lifestyles, satisfaction with local medical personnel, healthy lifestyles that do not rely on medical services, and desire for regional autonomy/desire to serve the region in terms of medical care. All of these themes were evident in both study areas. Thus, rather than relying on advanced medical services, both urban and rural Thai citizens expressed the desire to continue living within communities (considered as "families"), contributing to them, and tending to all of their health care needs within their communities.

Conclusions: This study revealed five common themes relating to forms of medical care regarded as ideal among urban and rural citizens of Thailand. Its findings could potentially have important implications for areas characterized by urban-rural inequities relating to the accessibility and utilization of medical services.

Keywords: Thailand, Medical care ideals, Urban, Rural, Grounded theory

\section{Background}

\section{Study context and objectives}

Urban and rural/remote communities differ in their utilization of medical care. Specifically, health care values are generally considered to be more pronounced in urban areas than in rural areas [1-13]. For example, Sewo et al. [14] have reported a higher total mean score for the quality of life (QOL) among urban residents compared with those in rural areas. However, Yiengprugsawan et al. [15] found that Thai Mental Health Indicators

\footnotetext{
* Correspondence: tomoki@ikaike.jp

${ }^{1}$ Division of Primary Health Care, Faculty of Medical Sciences, University of Fukui, 23-3 Matsuoka-shimoaizuki, Eiheiji-cho, Yoshida-gun, Fukui 9101193, Japan

Full list of author information is available at the end of the article
}

(TMHIs) of cohorts in urban and rural areas in Thailand did not differ significantly from each other. Thus, previous studies have found that health care values do not differ between Thai urban and rural areas, with some indicating that a higher value is placed on these values in rural areas [16-18].

Consequently, we conducted interviews and a qualitative investigation and analysis aimed at elucidating ideals relating to the medical environment among Thai urban and rural citizens. The insights and findings gained in the context of Thailand will, we hope, contribute to resolving worldwide inequity in health care. 


\section{Study setting}

The Kingdom of Thailand is situated in continental Southeast Asia (just north of the equator) and is part of the Indo-China Peninsula. Thailand covers an area of about $514,000 \mathrm{~km}^{2}$. Between its furthest points, from north to south, the distance is $1,860 \mathrm{~km}$. The country comprises 76 provinces, with mountainous terrain and basins in the north and a fertile delta area around the Chao Phraya River in the central region. The southern region is surrounded by the South China Sea and the Indian Ocean. The Thai ethnic group is dominant in the country, with most citizens being Buddhist [19]. Approximately $40 \%$ of Thai citizens are engaged in agriculture, which accounts for just $12 \%$ of the GDP. Moreover, approximately $15 \%$ of citizens are engaged in manufacturing, which accounts for $34 \%$ of the GDP and nearly $90 \%$ of exports [20]. Thailand's population comprises 64 million people. The ratio of doctors to the total population is approximately 0.32 for every 1000 people-approximately one-tenth of the average of OECD countries, that is, 3.3 per 1000 people. Further, more than 100,000 professional nurses contribute to primary health care. Approximately one million health care volunteers, who have undergone training, constitute additional medical personnel, mainly in farming villages. Thailand's citizens as well as medical personnel are highly concentrated in the capital, Bangkok, whereas medical care personnel are scarce in other areas. Thus, in 2009, while there were 1.77 doctors for every 1,000 people in Bangkok, the corresponding figure for the country's northeastern region was just 0.35 doctors for every 1,000 people. Similarly, the population/bed ratio in Bangkok was 312 and that of the northeast region was 779. The ratio of medical devices such as CT and MRI machines evidenced the same regional difference. Although the average lifespan in the country was 71.7 years from 2005 to 2010, the morbidity rates for urban and rural regions differed. Provinces with ample health resources (low population/doctor and population/bed ratios) had higher medical facility utilization rates. Additionally, these indices evidenced a clear bias in relation to rusticity in each region [19].

For this study, we selected the city of Khon Kaen, located in Khon Kaen Province in northeastern Thailand as the urban area, and Donyang village, located in the same province, as its rural counterpart. Khon Kaen has a population of approximately 120,000 people, making it one of the largest cities in northeastern Thailand. The city is located at the intersection of two important Southeast Asian transportation routes, namely, an eastwest route linking Myanmar and Vietnam and a northsouth route linking Bangkok and Laos. Donyang village has a population of 2,600 people, mostly engaged in agriculture. It is located approximately $15 \mathrm{~km}$ from the outskirts of Khon Kaen, and can be accessed by car from this city in approximately 30 minutes. There is no hospital in Donyang village; only a primary care clinic staffed by a doctor, who is only available on Mondays, and community nurses who are available on other days.

In 2001, Thailand launched a national health insurance program to provide universal health insurance coverage, popularly known as "30-baht health care" (health insurance with 30 baht deductible for every consultation or for hospitalization). More than $90 \%$ of Thai citizens are enrolled in health insurance [21]. While socioeconomic disparities exist in both urban and rural areas [22], under the universal health insurance coverage scheme, primary health care access among socioeconomically disadvantaged individuals has improved dramatically [23].

\section{Methods}

\section{Participants}

The current study targeted residents of urban and rural areas of Thailand, namely, the city of Khon Kaen and Donyang village. We contacted nurses engaged in health management in the village, explaining the general purpose of the study to them in advance and informing them of the interview date. On the day of the interview, we read out a document to the gathered participants that explained the study's purpose and significance, its methods, duration, how participants were selected, logistical considerations, and publication venue. This document was then shared with them. We confirmed their agreement to participate in the study, using a written informed consent form, before conducting the interviews.

\section{Data collection}

In July 2014, we conducted semi-structured interviews with the participants. All interviews were conducted with the facilitation of a local interpreter. To ensure consistency of interview content, smooth progression of the interviews, and collection of nonverbal sensory information, interviews were only conducted by the primary researcher using the same interpreter. We applied the interview guide, shown in Table 1. This was successfully used in a similar study conducted in Japan to clarify medical care ideals [24].

Group interviews involving two to three people were conducted. These were considered as separate interviews if the group members changed. In accordance with the memos, and any other relevant information obtained such as "medical experiences affected attitude to medical care ideals," we added interviewees who had undergone medical admission for our theoretical sampling. The interviews were held at public locations such as meeting halls and temples, or at participants' homes. They were recorded with a digital recorder, and transcripts were produced based on the interpreter's statements. Moreover, 
Table 1 Interview Guide

1 Out of all the medical care that you, your family, or acquaintances have received to date, what sort of medical care would you describe as "good" medical care? Why do you think it was good?

2 Conversely, what sort of medical care would you describe as "not good"? Why?

3 Do you think that the medical care you get in your own community is better than that in other communities? Do you think it is worse? What sort of communities do you think have worse medical care, and which do you think have better? Why do you think this?

4 What sort of medical care would you consider to be ideal for you?

during the interviews, the appearance, attitude, and general impression obtained of each participant were recorded, and these were used for analyzing nonverbal data. We analyzed the interviews, by date, in chronological order. The participants could leave after we had confirmed that theoretical saturation had been reached in each area and that no new ideas could be obtained.

\section{Data analysis}

The grounded theory research approach emphasizes inductive analysis. Deduction, which is the usual form of analytic thinking applied in medical research, proceeds from the general to the particular. It begins with preexisting hypotheses or theories, and entails data collection aimed at testing these theories. Conversely, induction proceeds from the particular to the general, and entails the development of new theories or hypotheses based on many observations. The emphasis on induction within studies that apply grounded theory means that they tend to adopt a very open approach regarding the process being studied. A study based on grounded theory may evolve as the researchers become aware of what the study participants consider to be important [25]. For this study, we applied a Constructivist Grounded Theory (CGT) approach [26]. Grounded theory is a qualitative method of analysis proposed and developed by Glaser and Strauss [27-29]. Grounded theory does not adequately attend to the process of data production because of its prior objectivist empirical tradition. By contrast, data and analysis relating to the modified CGT approach formulated by Charmaz [30] focus on phenomena associated with research subjects, as constructed through experiences and relationships forged with researchers. The CGT approach assumes that data and theories are neither emergent nor discovered. Rather, they are mutually "constructed" by the researcher and the research participant. It emphasizes the importance of studying the extent to which the research subjects' experiences are embedded in concepts that are less likely to surface such as positional networks, situations, and relationships. CGT has been recommended as an appropriate method for situations wherein researchers wish to understand the true feelings of participants in a variety of situations. It is best suited to addressing research questions that explore the complexities of cross-cultural issues and the abstract nature of the global mindset concept, along with the meanings assigned by participants to these issues as they frame them within the contexts of their own lives [31].

Based on the experiences, feelings, and attitudes of individual research participants, we elicited the elements of ideal medical care. We subsequently arranged these within storylines; repeated initial and focused coding, as well as sampling for each of the two areas; and elaborated on themes based on impressions, information, and memos obtained from the interviews. Analyses were performed for the new themes while repeatedly revisiting the original data and themes. Based on a focused consideration of data from one region, or alternatively, a consideration of data from another region, characteristic themes for the entire region were established for the theoretical coding. As the overall flow of the interviews and non-verbal information were required to accomplish this, a consistent approach was ensured through the performance of the analysis by just the primary researcher. The MAXQDA v.10 software (www.maxqda.com) was used to perform the analysis. MAXQDA is a convenient software package for conducting qualitative analysis of transcript data, enabling the aggregation of code frequency, data analysis by code segments and the creation of code matrices.

\section{Ethical approval}

Ethical approval for this study was granted by the Ethics Committees, Faculty of Medical Sciences, University of Fukui (Ethics Hearing -26-56).

\section{Results \\ Sample}

The study included 17 participants (15 females), whose ages ranged from 41 to 83 years. Basic data for participants in each area, such as the number of participants, the proportion of males and females, education and income levels, and prior histories of medical care are shown in Table 2.

\section{Themes}

Five major themes were identified. These were: locally appropriate standards of medical care, support for local lifestyles, satisfaction with local medical personnel, healthy lifestyles that do not rely on medical services, 
Table 2 Profiles of Participants Interviewed about Ideal Health Care in Thailand

\begin{tabular}{|c|c|c|c|}
\hline \multicolumn{2}{|l|}{ Characteristics } & Urban $(N=10)$ & Rural $(N=7)$ \\
\hline \multicolumn{2}{|l|}{ Females } & 8 & 7 \\
\hline \multicolumn{2}{|l|}{ Mean age at interview } & 54.6 & 60.0 \\
\hline \multirow[t]{6}{*}{ Highest level of education } & Graduation from lower elementary division (Grade 4) & $1(10.0 \%)$ & $7(57.1 \%)$ \\
\hline & Graduation from upper elementary division (Grade 7) & $2(20.0 \%)$ & $1(14.3 \%)$ \\
\hline & Graduation from lower middle division (Grade 10) & $2(20.0 \%)$ & $0(0.0 \%)$ \\
\hline & Graduation from upper middle division (Grade 12) & $2(20.0 \%)$ & $0(0.0 \%)$ \\
\hline & Graduation from higher education (two years) & $1(10.0 \%)$ & $0(0.0 \%)$ \\
\hline & Graduation from higher education (four years) & $2(20.0 \%)$ & $2(28.6 \%)$ \\
\hline \multirow[t]{5}{*}{ Household income } & Less than 200,000 baht & $3(30.0 \%)$ & $1(14.3 \%)$ \\
\hline & 200,000 baht $-400,000$ baht & $4(40.0 \%)$ & $2(28.6 \%)$ \\
\hline & 400,000 baht $-600,000$ baht & $0(0.0 \%)$ & $2(28.6 \%)$ \\
\hline & 600,000 baht $-800,000$ baht & $2(20.0 \%)$ & $2(28.6 \%)$ \\
\hline & 800,000 baht or more & $0(0.0 \%)$ & $0(0.0 \%)$ \\
\hline \multicolumn{2}{|c|}{ Number of respondents who visited a hospital or clinic on a regular basis (\%) } & $8(80.0 \%)$ & $5(71.4 \%)$ \\
\hline \multirow[t]{4}{*}{ Experience of hospital admissions (\%) } & Never & $2(20.0 \%)$ & $3(42.8 \%)$ \\
\hline & $1-2$ & $4(40.0 \%)$ & $1(14.3 \%)$ \\
\hline & $3-5$ & $2(20.0 \%)$ & $1(14.3 \%)$ \\
\hline & 6 times or more & $2(20.0 \%)$ & $2(28.6 \%)$ \\
\hline
\end{tabular}

and desire for regional autonomy/desire to serve the region in terms of medical care. All of these themes were observed in both study areas.

\section{Locally appropriate standards of medical care}

Two focused codes were extracted for the theme, locally appropriate standards of medical care. These were: "the degree of advancement, degree of specialization, personnel, number of facilities, and medical devices met local needs" and "consultations were not refused," Examples of relevant statements made by four participants in relation to this theme are listed below. Participant Rural02 described ideals relating to medical technology within institutions. Participant Rural05 opined that a minimum level of medical care was required in the area, entailing the provision of guaranteed consultations for citizens. Participant Urban01 believed that the personnel and facilities were not appropriate for the area. Last, according to Participant Urban06, a minimum level of service should be provided, and lack of human resources should be acknowledged. Further, citizens should be allowed to choose the medical institution for their treatment.

We have two general hospitals nearby: Hospital $A$, which is public, and Hospital B, which is private. I think both of them have good systems. I think hospitals should have medical devices for examining and diagnosing illnesses. These hospitals have those. (Participant Rural02)
You won't be refused a consultation at the public hospital. When you need something, you should at least be able to get a minimum level of service. (Participant Rural05)

I've heard that there are some places [hospitals] that don't have enough space and personnel in the city, too. I've heard that sometimes the hospitals put patients in the hallways. They should have more employees and facilities, because there is a shortage of these in the area. (Participant Urban01)

There definitely are not enough doctors, and I don't think there are enough [of] other medical personnel either. I'd like to be able to choose [the medical institution]. (Participant Urban06)

\section{Support for local lifestyles}

The theme of support for local lifestyles comprised ideals held by residents regarding the medical services that they required to be able to continue living in their respective areas. This theme included the following focused codes: "accessibility in terms of distance" and "fees for treatment that enables a sustainable lifestyle." Three examples of statements made by participants are presented below. Participant Urban08 spoke about road conditions and the accessibility of hospitals, and Participant Rural03 spoke about the accessibility of nearby clinics. Participant 
Rural04 spoke about medical fees paid by patients themselves under the Thai medical system, as well as the ease of living.

You can get there [to the hospital] in a few minutes by car, so it's convenient. The roads are not bad [they are paved]. (Participant Urban08)

A primary health care clinic opened $5 \mathrm{~km}$ from here, three years ago, so it's easier [to get a consultation]. Before, we had to go out of our way and travel very far. (Participant Rural03)

In Thailand, we have the 30-baht system, so most people can have a consultation for 30 baht. You can get aid if your income is low, so life is easy. (Participant Rural04)

\section{Satisfaction with local medical personnel}

This theme comprised two main vectors: distance and communication. The first vector, distance, indicated satisfaction relating to the presence of medical personnel such as community nurses and volunteers, as well as medical facilities in the vicinity. It was associated with focused codes such as "accessibility to medical personnel" and "comprehensiveness of medical care in the area." The second vector, communication, indicated satisfaction based on the recognition that citizens were being watched over by medical personnel, or that they were understood by these personnel. Focused codes associated with this vector included "awareness of being watched over," "kindness of medical personnel," and "ease of exchanging information with medical personnel." Four illustrative statements by participants are presented below. Participant Urban10 expressed satisfaction with the accessibility of medical care as volunteers made rounds to see patients. Participant Rural06 described an ideal situation of inpatient and outpatient treatment by medical personnel in the area. Participant Urban02 expressed satisfaction relating to the awareness of being watched over by citizen volunteers. Last, Participant Rural07 was satisfied with community nurses' understanding of the needs of the area.

Volunteers make rounds to see us and care about our health. Thanks to them, we can get detailed information about health in the area, so we trust them and rely on them. (Participant Urban10)

I'd be more satisfied if nearby primary care clinics would care for us even when we need inpatient treatment. I want to be cared for in the same area by the same nurses. I don't want to go to the hospital. (Participant Rural06)
The volunteers care for us and understand us, so I'm satisfied. (Participant Urban02)

The community nurses really know everything about the area. They know who lives where, what illnesses they have, and what type of life they live. I think they might even know more than those of us who live here. (Participant Rural07)

\section{Healthy lifestyles that do not rely on medical services}

The theme of healthy lifestyles that do not rely on medical services focused not only on attempts to extend life and cure illnesses through medical services, but also on living in such a way that medical services were not required. It entailed focused codes such as "prevention and access to medical information for improving health" and "reliance on folk, traditional, and spiritual treatment methods." Three relevant examples of statements by participants are presented here. Participant Urban05 described a cultural preference for traditional care over modern medicine, because citizens were not inclined to visit hospitals. Participant Rural01 was satisfied with medical treatment, because the participant was physically able to take care of herself. Participant Rural06 desired knowledge and guidance from medical personnel on health maintenance.

Even when we don't feel well, we don't go to the hospital right away. That's because of a foundation of cultural beliefs that folk treatments, or spiritual treatments such as religious purification, can cure illnesses. This may be why few people are inclined to go to the hospital. (Participant Urban05)

There is a clinic nearby, and we take care of our health on our own ... I think the current medical environment is good enough. (Participant Rural01)

If we had doctors who would look more at the living environment, including prevention and improvement of health, our medical care would be better.

(Participant Rural06)

Desire for regional autonomy/desire to serve the region in terms of medical care

The theme relating to desire for regional autonomy/desire to serve the region in terms of medical care is a particularly interesting one that was evident in focused codes such as "regional activities by community members (voluntary, care for the elderly)," "family unity in the area," "desire to contribute to the area," "being considerate of one another," and "respect for ancestors." Three related statements by participants are presented below. Participant Urban07 described a personal connection to 
the area, as well as the importance of contributing to the area. Participant Urban08 described care for the elderly and regional initiatives undertaken by local groups with government support. Participant Rural01 felt that activities by citizens in the area strengthened regional unity, contributing to the actualization of ideal medical care.

Traditional Thai society involves an awareness of all the citizens in the area [being] relatives [one family]. The culture puts a high value on contributing to the family and the area, and we are taught not to forget this from childhood. We think the same way about implementing medical care. (Participant Urban07)

Everyone in the area gathers on Buddhist holidays to take care of the elderly. The elderly are the most highly valued people in the villages. The people apply for their own health promotion projects and take action with financial support from the government. (Participant Urban08)

I think that the activities by volunteers themselves strengthen regional unity. In cities, people are not around their families and there is a weak connection to the area. So probably people won't cooperate with each other unless something brings them together. (Participant Rural01)

\section{Discussion}

Previous studies have generally indicated that there are disparities in accessibility and utilization of medical care between urban and rural areas [7-13]. Some studies have reported that there are variations in the medical environment between urban and rural areas in Thailand $[23,32-34]$. We, therefore, investigated why, in contrast to these findings, our study did not find any difference between urban and rural areas in terms of medical care ideals held by their residents. One unique aspect of the identity lies in the lack of ideals relating to medical skills and procedures. Rather than desiring advanced medical technology, Thai citizens appear to prefer a healthy lifestyle that is not dependent upon medical services. Citizens emphasized their lifestyles in their areas over the nature of medical care in relation to themes such as support for local lifestyles, satisfaction with local medical personnel, and desire for regional autonomy/desire to serve the region in terms of medical care. In fact, they may not have understood the benefits of advanced medical care, as indicated by the following statement by Participant Rural05: "I don't know what kind of services they provide at hospitals." This view appears to be endorsed by Miedema, Easley, and Robinson based on their interviews of cancer patients in urban and rural areas [35]. These demonstrated the high expectations of urban residents relating to medical care and, conversely, the low expectations of residents of remote areas relating to such care, influencing their degree of satisfaction [35]. However, the reason for this finding was revealed through another theme examined in this study, namely, desire for regional autonomy/desire to serve the region in terms of medical care. As stated by Participant Urban07: "All the citizens in the area are related [one family]." There is a strong sense within the community of being a family, and in the past, this family was responsible for health care functions. Thus, the scope of existing criteria such as QOL for evaluating medical care appears to be limited. Martin et al. observed that QOL in Khon Kaen was strongly influenced by family, money, accommodation, and employment, in addition to health [36]. Yiengprugsawan et al. noted that in Thailand, the three most influential factors relating to happiness were the standard of living, future security, and life achievement [19]. In addition, Jongudomkarn and Camfield found that there were limitations relating to the quantitative measurement of the quality of health care using QOL, because Thai citizens emphasize basic criteria such as significant primary relationships [37]. This could explain the possible occurrence of shared ideals when citizens feel a sense of belonging, despite differences between urban and rural areas. Because basic criteria emphasized by Thai citizens, as identified in this study, can be explained by defining health literacy in terms of a family/society network, and health information [38], we feel that these are appropriate for the result of the current study.

Additionally, the findings of several previous studies match those of this study. Unlike in other countries, there is no difference in the physical health and happiness of urban and rural residents in Thailand [18]. Large-scale cohort studies have found no differences in the happiness of urban and rural residents in Thailand [15]. This explains the lack of differences in criteria for evaluating medical services, even though medical environments differ in Thailand. We should not, therefore, conclude that evaluations of medical services and views on medical care change based on accessibility and use of medical resources in Thailand.

This study had a number of limitations. First, the participants were not randomly sampled. Consequently, there may have been imbalances in relation to sex, age, academic history, income, and medical history among them. They cannot, therefore, be generalized. Sobieszczyk et al. have affirmed that no major differences exist regarding gender and well being among elderly people in Thailand [39]. By contrast, Sumngern et al. noted that there was a significant difference in the happiness of elderly people in urban and rural areas within the Thai province of Chonburi [40]. Additionally, Coronini-Cronberg et 
al. observed that even in an extremely impoverished area like Khon Kaen, health care was well-used [21], while Mordacci and Sobel found that personal views on health and medical history often influenced ideas and cultures on health [41]. However, the findings of these studies are not consistent, and we believe that our study appropriately reveals one aspect of healthcare in Thailand.

While this study targeted the areas of Khon Kaen and a nearby rural village, there is no evidence to support generalization of its findings as being representative of urban and rural areas across Thailand. Findings for provinces other than Khon Kaen may differ. Regional unity, accessibility, and use of health care facilities, would likely differ in a metropolitan area such as Bangkok, which has more migrants than Khon Kaen city, and in communities that are more rural in character than Donyang village, thus yielding different results. Future research will, therefore, need to gather data from a more diverse range of regions.

\section{Conclusion}

This study has uncovered five prevalent themes relating to forms of medical care regarded as ideal by citizens in urban and rural areas of Thailand. These are: locally appropriate standards of medical care, support for local lifestyles, satisfaction with local medical personnel, healthy lifestyles that do not rely on medical services, and desire for regional autonomy/desire to serve the region in terms of medical care. Rather than relying on advanced medical services, citizens prefer to continue living in communities (which they regard as "families"), to contribute to their communities, and to meet all of their health care needs from within their communities. The findings of this study could potentially make a positive contribution in regions where there are inequities in the accessibility and use of medical services between urban and rural areas. A number of studies have observed that forms of social capital such as regional ties and trusting relationships have socio-epidemiological implications for health $[42,43]$. We believe that our results will extend and deepen this body of knowledge.

\section{Competing interests}

The authors declare that they have no competing interests.

\section{Authors' contributions}

$\mathrm{Tl}$ carried out the interviews, mainly analyzed in this study and drafted the manuscript. SY and TT had set monitored the interviews and add Thai and Japanese information about medical systems. TT, HK, KS, YK, HH and HT also analyzed the interview and discussed the result each other. All authors read and approved the final manuscript.

\section{Authors' information}

TI: M.D., Ph.D. Senior Assistant Professor of Division of Primary Health Care, Faculty of Medical Sciences, University of Fukui.

SY: Dean of Faculty of Nursing, College of Asian Scholars

TT: Associate Professor of Headquarters for Innovative Society-Academia

Cooperation, University of Fukui
IT: M.D., Ph.D. Assistant Professor of Division of Environmental Health, Department of International and Social Medicine, Faculty of Medical Sciences, University of Fukui

HK: M.D., Ph.D. Assistant Professor of Division of Environmental Health,

Department of International and Social Medicine, Faculty of Medical

Sciences, University of Fukui

KS: M.D., Ph.D. Associate Professor of Division of Environmental Health,

Department of International and Social Medicine, Faculty of Medical

Sciences, University of Fukui

YK: M.D., Ph.D. Professor of Division of Environmental Health, Department of International and Social Medicine, Faculty of Medical Sciences, University of Fukui

HH: M.D. Professor of Division of General Internal Medicine, Faculty of

Medical Sciences, University of Fukui

HT: M.D. Professor of Division of Promotion of Community Medicine, Faculty of Medical Sciences, University of Fukui

\section{Acknowledgment}

This work was supported by the Ministry of Education, Culture, Sports, Science and Technology and the University of Fukui under the "Center of Community (COC)" program (2014).

\section{Compliance with Ethical Standards}

Disclosure of potential conflicts of interest: The authors have declared that no competing interests exist. Ethical approval for this study was granted by the Ethics Committees, Faculty of

Medical Sciences, University of Fukui (Ethics Hearing 26-56). When the participant candidates gathered on the interview date, we read to them a document that explained the survey's significance and purpose, methods, dates, selection of subjects, logistical considerations, and then passed it to them. We confirmed their participation using a written informed consent form before being interviewed.

\section{Author details}

'Division of Primary Health Care, Faculty of Medical Sciences, University of Fukui, 23-3 Matsuoka-shimoaizuki, Eiheiji-cho, Yoshida-gun, Fukui 9101193, Japan. ${ }^{2}$ Faculty of Nursing, College of Asian Scholars, Khon Kaen, Thailand. ${ }^{3}$ Headquarters for Innovative Society-Academia Cooperation, University of Fukui, Fukui, Japan. ${ }^{4}$ Division of Environmental Health, Department of International and Social Medicine, Faculty of Medical Sciences, University of Fukui, Fukui, Japan. ${ }^{5}$ Division of General Internal Medicine, Faculty of Medical Sciences, University of Fukui, Fukui, Japan. ${ }^{6}$ Division of Promotion of

Community Medicine, Faculty of Medical Sciences, University of Fukui, Fukui, Japan.

Received: 6 August 2015 Accepted: 23 December 2015

Published online: 05 January 2016

\section{References}

1. De La Rue M, Coulson I. The meaning of health and well-being: voices from older rural women. Rural Remote Health. 2003;3:192.

2. lezzoni LI, Killeen MB, O'Day B. Rural residents with disabilities confront substantial barriers to obtaining primary care. Health Serv Res. 2006;41: 1258-75. doi:10.1111/j.1475-6773.2006.00534.x.

3. Asnani M, Reid ME, Ali SB, Lipps G, Williams-Green P. Quality of life in patients with sickle cell disease in Jamaica: rural-urban differences. Rural Remote Health. 2008:8:890

4. Oguzturk O. Differences in quality of life in rural and urban populations. Clin Invest Med. 2008;31:E346-50.

5. Baoren S. Leisure life of elderly residents in China: a case study of difference between rural and urban area. Asian Soc Sci. 2009;4(11):100.

6. Zhou B, Chen K, Wang J, Wang H, Zhang S, Zheng W. Quality of life and related factors in the older rural and urban chinese populations in Zhejiang Province. J Appl Gerontol. 2001;30:199.

7. Kobayashi Y, Takaki H. Geographic distribution of physicians in Japan. Lancet. 1992;340:1391-3. doi:10.1016/0140-6736(92)92569-2.

8. Larson SL, Fleishman JA. Rural-urban differences in usual source of care and ambulatory service use: analyses of national data using Urban Influence Codes. Med Care. 2003;41:11165-74.

9. Liu M, Zhang Q, Lu M, Kwon CS, Quan H. Rural and urban disparity in health services utilization in China. Med Care. 2007;45:767-74. 
10. Goodridge D, Lawson J, Rennie D, Marciniuk D. Rural/urban differences in health care utilization and place of death for persons with respiratory illness in the last year of life. Rural Remote Health. 2010;10:1349.

11. Menec VH, Nowicki S, Kalischuk A. Transfers to acute care hospitals at the end of life: do rural/remote regions differ from urban regions? Rural Remote Health. 2010;10:1281.

12. Salinas JJ, Al Snih S, Markides K, Ray LA, Angel RJ. The rural-urban divide: health services utilization among older Mexicans in Mexico. J Rural Health. 2010;26:333-41. doi:10.1111/j.1748-0361.2010.00297.x.

13. Rica M, Curtis S, Norman P. Residential mobility within England and urbanrural inequalities in mortality. Soc Sci Med. 2011;73:1698-706. doi:10.1016/j. socscimed.2011.09.030.

14. Sewo S, Priscila Y, Ito E, Carvalho S, Ricardo A. The association of activity and participation with quality of life between Japanese older adults living in rural and urban areas. J Clin Gerontol Geriatr. 2013;4:51-6. doi:10.1016/j.jcgg. 2012.11.004

15. Yiengprugsawan V, Somboonsook B, Seubsman S, Sleigh A. Happiness, mental health, and socio-demographic associations among a national cohort of Thai adults. J Happiness Stud. 2012;13:1019-29. doi:10.1007/ s10902-011-9304-4

16. Woodcock A, Camfield L, Mcgregor JA, Martin F. Validation of the WeDQoLgoals-Thailand measure: culture-specific individualised quality of life. Soc Indic Res. 2009;94:135-71. doi:10.1007/s11205-008-9357-x.

17. Yiengprugsawan V, Seubsman S, Khamman S, Lim LLY, Sleigh AC. Personal wellbeing index in a national cohort of 87,134 Thai adults. Soc Indic Res. 2010;98:201-15. doi:10.1007/s11205-009-9542-6.

18. Pholphirul P. Healthier and happier? The urban-rural divide in Thailand. J Hum Behav Soc Environ. 2014;24:973-85. doi:10.1080/10911359.2014.945064.

19. Wibulpolprasert S. Thailand Health Profile 2008-2010. Bangkok: WO Office of Printing Mill, The War Veteran Organization of Thailand; 2010.

20. National Economic and Social Development Board. Flow-of-Funds Accounts of Thailand. Available: http://eng.nesdb.go.th/Default.aspx?tabid=99. Accessed 01 January 2015

21. Coronini-Cronberg S, Laohasiriwong W, Gericke CA. Health care utilisation under the 30-Baht Scheme among the urban poor in Mitrapap slum, Khon Kaen. Thailand Int J Equity Health. 2007:6:11.

22. Zimmer Z, Prachuabmoh V. Comparing the socioeconomic status-Health gradient among adults 50 and older across rural and urban areas of Thailand in 1994 and 2007. Soc Sci Med. 2012;74:1921-8. doi:10.1016/j. socscimed.2012.02.015

23. Yiengprugsawan V, Carmichael GA, Lim LLY, Seubsman SA, Sleigh AC. Has universal health insurance reduced socioeconomic inequalities in urban and rural health service use in Thailand? (Report) Health Place. 2010;16:1030.

24. Ikai T, Suzuki T, Oshima T, Kanayama H, Kusaka Y, Hayashi H, Terasawa H. What sort of medical care is ideal? Differences in thoughts on medical care among residents of urban and rural/remote Japanese communities. Health Soc Care Community. 2015; Epub ahead of print. doi:10.1111/hsc.12271.

25. Sbaraini A, Carter SM, Evans RW, Blinkhorn A. How to do a grounded theory study: a worked example of a study of dental practices. BMC Med Res Methodol. 2011;11:128. doi:10.1186/1471-2288-11-128.

26. Charmaz K. Grounded theory: objectivist and constructivist methods. In Denzin N, Lincoln YS, editors. Handbook of Qualitative Research. 2nd ed. Thousand Oaks: Sage Publications Inc; 2000.

27. Glaser BG, Strauss AL. The discovery of grounded theory. Chicago: Aldine; 1967.

28. Glaser BG. Theoretical sensitivity. Mill Valley: Yhe Sociology Press; 1978

29. Corbin J, Strauss AL. Grounded theory research: Producers, canons, and evaluative criteria. Qual Sociol. 1990;13:3-21.

30. Charmaz K. Constructing grounded theory: A practical guide through qualitative analysis. London: Sage Publications Ltd; 2006.

31. Wilson W. Constructive Grounded Theory in the Search for Meaning on Global Mindedness: a Novice Researcher's Guide. Hill Top Barn, Elsfield Oxford. OX3 9UH; 2012.

32. Limwattananon S, Tangcharoensathien V, Prakongsai P. Equity in maternal and child health in Thailand. Bull World Health Organ. 2010;88:420. doi:10.2471/BLT.09.068791.

33. Nishiura H, Barua S, Lawpoolsri S, Kittitrakul C, Leman MM, Maha MS, et al. Health inequalities in Thailand: geographic distribution of medical supplies in the provinces. Southeast Asian J Trop Med Public Health. 2004;35:735-40.

34. Pongchaiyakul C, Hongsprabhas P, Pisprasert V, Pongchaiyakul C. Ruralurban difference in lipid levels and prevalence of dyslipidemia: a population-based study in Khon Kaen province, Thailand. J Med Assoc Thai. 2011:89:1835-44

35. Miedema B, Easley JK, Robinson LM. Comparing urban and rural young adult cancer survivors' experiences: a qualitative study. Rural Remote Health. 2013;13:2324

36. Martin F, Rodham K, Camfield L, Ruta D. Reliability and validity of the Thai "Global Person Generated Index", an individualised measure of quality of life. Appl Res Qual Life. 2010;5:219-32. doi:10.1007/s11482-010-9106-6.

37. Jongudomkarn D, Camfield L. Exploring the Quality of Life of People in North Eastern and Southern Thailand. Soc Indic Res. 2006;78:489-529. doi:10.1007/s11205-005-1947-2.

38. Edwards M, Wood F, Davies M, Edwards A. 'Distributed health literacy': longitudinal qualitative analysis of the roles of health literacy mediators and social networks of people living with a long-term health condition. Health Expect. 2013; doi:10.1111/hex.12093

39. Sobieszczyk T, Knodel J, Chayovan N. Gender and wellbeing among older people: evidence from Thailand. Ageing Soc. 2003;23:701-35. doi:10.1017/ S0144686X03001429.

40. Sumngern C, Azeredo Z, Subgranon R, Sungvorawongphana N, Matos E. Happiness among the elderly in communities: A study in senior clubs of Chonburi Province, Thailand. Jpn J Nurs Sci. 2010;7:47-54. doi:10.1111/j. 1742-7924.2010.00139.x.

41. Mordacci R, Sobel R. Health: a comprehensive concept. Hastings Cent Rep. 1998:28:34-7.

42. Kawachi I, Kennedy BP, Lochner K, Prothrow-Stith D. Social capital, income inequality, and mortality. Am J Public Health. 1997:87:1491-8.

43. Kawachi I, Kennedy BP, Glass R. Social capital and self-rated health: a contextual analysis. Am J Public Health. 1999:89:1187-93.

\section{Submit your next manuscript to BioMed Central and we will help you at every step:}

- We accept pre-submission inquiries

- Our selector tool helps you to find the most relevant journal

- We provide round the clock customer support

- Convenient online submission

- Thorough peer review

- Inclusion in PubMed and all major indexing services

- Maximum visibility for your research

Submit your manuscript at www.biomedcentral.com/submit
) Biomed Central 